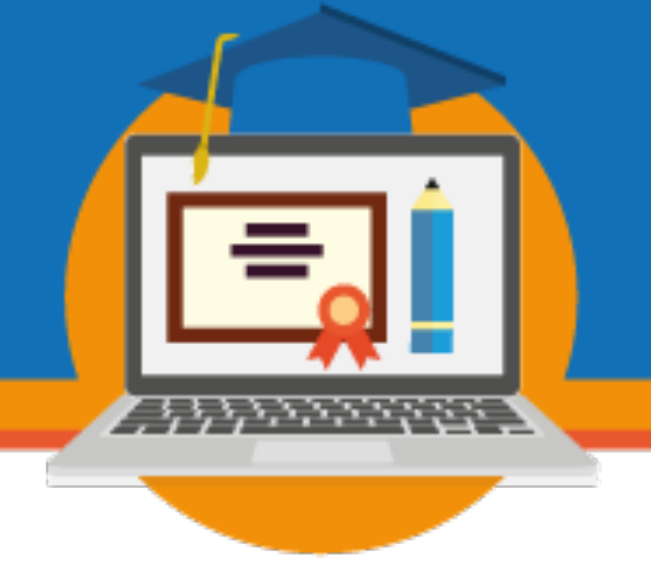

\title{
O MOODLE COMO APOIO AO ENSINO PRESENCIAL: A FASE DE AVALIAÇÃO DE UMA PROPOSTA COM DESIGN INSTRUCIONAL
}

\author{
Sabrina Bourscheid Sassi \\ Universidade Federal de Mato Grosso -UFMT \\ sabrinabsassi@gmail.com \\ Cristiano Maciel \\ Universidade Federal de Mato Grosso -UFMT \\ crismac@gmail.com \\ Vinícius Carvalho Pereira \\ Universidade Federal de Mato Grosso -UFMT \\ viniciuscarpe@gmail.com
}

Eixo 6: Tecnologias e Mediações Pedagógicas

\begin{abstract}
Resumo: A presença das tecnologias de informação e comunicação e seu uso na educação possibilitam a ressignificação das práticas pedagógicas, bem como novas perspectivas para o ensino e aprendizagem. O presente estudo, resultado de uma pesquisa de Mestrado em Educação da UFMT, aborda o uso de Ambientes Virtuais de Aprendizagem (AVA) com a adoção do design instrucional (DI) para a elaboração de estratégias e de recursos a serem empregados na aprendizagem, descrevendo de forma sucinta o planejar (análise, design e desenvolvimento) e o implementar, destacando o avaliar, com base nas percepções dos alunos do primeiro ano do ensino médio de uma escola estadual de um curso que deu apoio à disciplina de Matemática sob a ótica do Design Instrucional.
\end{abstract}

Palavras-chave: Design Instrucional. Moodle. Matemática.

\section{Introdução}

A presença das Tecnologias de Informação e Comunicação (TIC) e seu uso pela sociedade proporcionaram e ainda proporcionam mudanças em diferentes aspectos, inclusive o educacional. Não há como negar que as tecnologias chegaram às escolas e, apesar das resistências, as transformações que as TIC vêm promovendo levam a escola a analisar e refletir sobre a importância de conhecê-las e utilizá-las no ensino. 


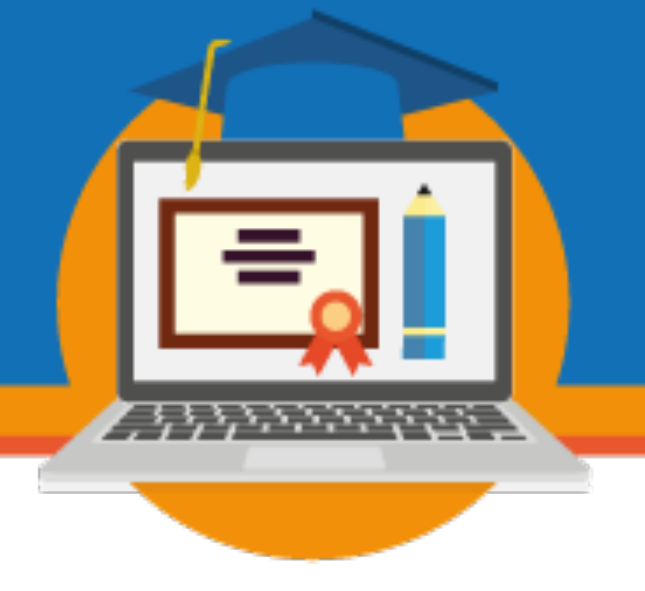

Diante do novo discente, da influência das TIC, das experiências da Educação a Distância $(\mathrm{EaD})$ e do regulamento' da oferta de cursos e programas de Ensino Médio, de Educação Profissional Técnica de Nível Médio e de Educação de Jovens e Adultos, no Ensino Fundamental e no Ensino Médio, na modalidade de EaD, surge a possibilidade de investigar contextos de ensino médio presencial apoiado por Ambiente Virtual de Aprendizagem (AVA).

O Ambiente Virtual de Aprendizagem "não suprime o espaço educacional presencial. Ao contrário, ele o amplia” (KENSKI, 2012, p.68) e é conceituado por Anjos (2013, p. 53, grifo do autor) como

[...] uma ou mais soluções de comunicação, gestão e aprendizado eletrônico, que possibilitam o desenvolvimento, integração e a utilização de conteúdos, mídias e estratégias de ensinoaprendizagem, a partir de experiências que possuem ou não referência com o mundo real e são virtualmente criadas ou adaptadas para propósitos educacionais.

Filatro (2008, p. 120) evidencia que o termo AVA "reflete mais apropriadamente o conceito de 'sala de aula on-line', em que a ideia de sistema eletrônico está presente, mas é extrapolada pelo entendimento de que a educação não se faz sem ação e interação entre as pessoas". No entanto, para utilizar um AVA como apoio ao ensino, é fundamental planejar para que a proposta educacional atenda ao contexto e aos objetivos.

Nesta perspectiva, surge o design instrucional, o qual compreendemos como um processo amplo, definido por Filatro (2008, p. 4) como uma "teoria, um corpo de conhecimento voltado à pesquisa e à teorização das estratégias instrucionais".

Neste cenário, propomo-nos relatar parte da implementação da proposta de Design Instrucional de um AVA para apoio à disciplina de Matemática no ensino presencial, analisando especificamente a fase de Avaliação do processo de Design Instrucional, com foco no aluno.

A opção metodológica que orienta a redação deste trabalho é um estudo de caso (STAKE, 2010) com abordagem qualitativa (MARTINS, 2004), com o objetivo de conhecer

\footnotetext{
${ }^{1}$ Resolução Número 1 da Câmara de Educação Básica do Conselho Nacional de Educação (CNE), publicada pelo Diário Oficial da União (DOU), no dia 03 de fevereiro de 2016 (BRASIL, 2016)
}

\section{SEMINÁRIO DE EDUCAÇÃO A DISTÂNCIA}




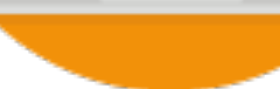

em profundidade e qualidade um caso - a adoção do AVA Moodle como ferramenta de apoio ao ensino de Matemática no ensino médio presencial em uma escola estadual de Mato Grosso. Para a consecução dos objetivos desta pesquisa, a geração de dados se baseou na observação e no questionário aplicado aos alunos que participaram da proposta.

\section{Design Instrucional}

O Design Instrucional (DI), por muitas décadas, esteve ligado aos materiais didáticos impressos, porém, com o desenvolvimento das TIC, essa atividade passa a ser entendida não somente como um produto final, mas como um processo mais abrangente, na condição de dinâmica que envolve vários agentes e etapas.

Filatro (2008, p. 3) define o DI como uma “[...] ação intencional e sistemática de ensino" e, como processo que identifica um problema de aprendizagem e, a partir deste, desenha, implementa e avalia uma solução para resolvê-lo, ou seja, uma ação que "[...] envolve o planejamento, o desenvolvimento e a aplicação de métodos, técnicas, atividades, materiais, eventos e produtos educacionais em situações didáticas específicas, a fim de promover, a partir dos princípios de aprendizagem e instrução conhecidos, a aprendizagem humana".

Entre os diferentes modelos que podem ser aplicados às práticas de Design Instrucional existentes, o processo de DI mais aceito e utilizado para o desenvolvimento de um ambiente é o ISD (Instructional System Design - Design de sistemas instrucionais), que divide o DI em cinco fases: análise, design, desenvolvimento, implementação e avaliação. Essa divisão em fases também é conhecida como modelo ADDIE (acrônimo de analysis, design, development, implementation e evaluation - análise, design, desenvolvimento, implementação e avaliação), que, na situação didática, separa o processo de DI em dois momentos, o da concepção (análise, design e desenvolvimento) e o da execução (implementação e avaliação) (FILATRO, 2008).

Embora a teoria de DI ofereça detalhadamente orientação sobre como alcançar os objetivos de aprendizagem, Svensson (2008) orienta que ela não deve ser considerada um único caminho a ser seguido, mas sim um modelo de instrução que pode ser utilizado em determinada 
situação didática. Filatro (2010, p. 131, grifo do autor) considera que, "como não existe um contexto perfeito de aplicação, também não existe uma única fórmula instrucional verdadeira". Frente aos variados contextos e padrões de utilização das tecnologias no ensino, segundo Filatro (2008) o modelo de DI a ser adotado também pode variar entre design instrucional fixo, aberto ou contextualizado.

O DI fixo, ou fechado, tem como característica um planejamento antecipado e bem programado, não prevendo alteração no decorrer do curso, ficando definido antes da formação de turmas. Ou seja, todas as decisões relacionadas a estrutura, conteúdo e interações são definidas antecipadamente (FILATRO, 2008).

O DI aberto tem como foco mais o processo de aprendizagem de um curso e a interação entre os educadores e alunos do que os conteúdos inseridos no AVA durante o curso. Neste molde, os conteúdos podem ser alterados no decorrer do curso, após a realização de uma avaliação processual e/ou diagnóstica e, geralmente, os cursos fazem uso de ambientes menos estruturados e com mais links que encaminham o aluno a referências externas (FILATRO, 2008).

O DI contextualizado (DIC) se aproxima do DI aberto, pois o ambiente a ser utilizado pode ser alterado e personalizado a qualquer momento, possibilitando ao aluno fazer parte do processo de construção do conhecimento, compartilhando com seus pares informações e experiências por meio de recursos como listas de discussão, redes sociais, wikis, fóruns etc. Esse modelo de DI concebe as cinco fases de desenvolvimento, mas foge dos padrões lineares contidos no DI fixo e aberto. Ou seja, as fases de análise, design, desenvolvimento, implementação e avaliação se sucedem durante todo o processo como uma espiral, repetindose em sequências de estágios em diferentes níveis, com mais detalhes e aprofundamento (FILATRO, 2008).

As cinco fases (análise, design, desenvolvimento, implementação e avaliações) que compõem o processo de DI, seja ele DI fixo, aberto ou contextualizado, são assim descritas: 


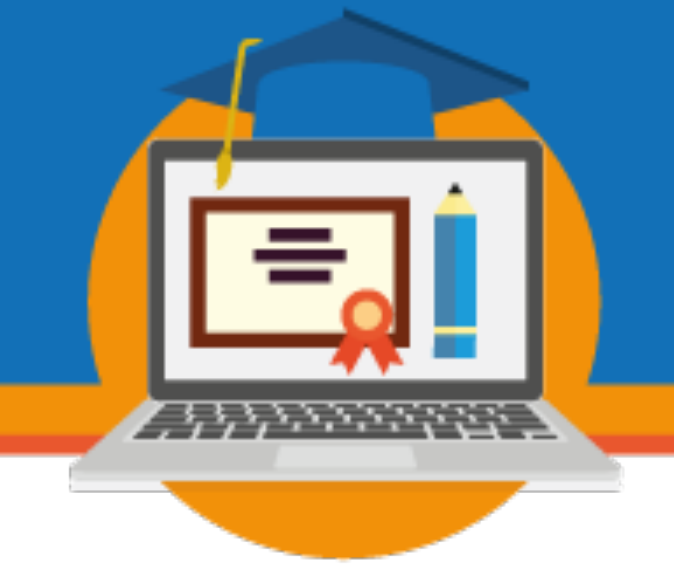

- Fase de Análise: Compreende entender o problema e projetar a solução aproximada. Nesta fase é realizada a caracterização dos alunos, a identificação das necessidades educacionais, a definição dos objetivos instrucionais e o levantamento das restrições existentes.

- Fase de Design: Abrange a compreensão do contexto, o planejamento e o design da situação didática. Nesta fase são elaborados os instrumentos (mapa, matriz e storyboard).

- Fase de Desenvolvimento: Compreende a produção e adaptação dos recursos de informação e comunicação, produção de material didático e parametrização do AVA.

- Fase de Implementação: Corresponde à situação didática em si. Nesta fase é realizada a capacitação dos usuários do AVA, a ambientação e a aplicação da proposta.

- Fase de Avaliação: Abrange as considerações sobre a eficiência da solução proposta. Compreende o acompanhamento da situação de ensino-aprendizagem, a revisão das fases do DI e a identificação dos fatores que podem ser melhorados para a atual (ou uma futura) proposta.

\section{Contextualização da pesquisa}

Nesta seção, apresentamos brevemente a implementação da proposta de Design Instrucional de um AVA como apoio à disciplina de Matemática no Ensino Médio presencial, desenvolvida com 11 alunos de uma turma de primeiro ano do período vespertino e o professor regente da disciplina de Matemática de uma Escola Estadual de Sorriso-MT, com o objetivo de disponibilizar aos alunos conteúdos e atividades extraclasse para a disciplina de Matemática. Tanto o professor quanto os alunos participaram de forma voluntária.

\section{SEMINÁRIO DE EDUCAÇÃO A DISTÂNCIA}




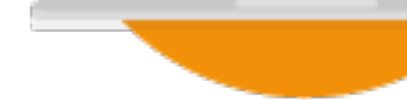

A proposta foi dividida em três momentos distintos. O primeiro compreende as fases de análise, design e desenvolvimento do DI, que ocorreram antes da situação didática e fundamentaram-se na análise do contexto, na elaboração da proposta do DI aberto e na parametrização do AVA Moodle.

$\mathrm{Na}$ fase de análise, que consiste em analisar o contexto a fim de identificar as principais variáveis que podem favorecer ou restringir o processo de ensino-aprendizagem, foram levantadas informações com base em documentos como o Plano Político Pedagógico (P.P.P), o Regimento da Escola, as informações do Censo Escolar de 2014 e o Planejamento Anual de ensino de Matemática da escola. Além disso, também foram realizadas observações livres na escola, entrevistas livres com coordenadores e técnico do laboratório, entrevista semiestruturada com o professor e aplicação de questionário estruturado aos alunos. Com base nas informações colhidas, foi elaborado um relatório quanto às necessidades de aprendizagem, as restrições existentes e a caracterização dos alunos, sugerindo recomendações para o design do AVA.

A fase de design tem como base os dados gerados na análise do contexto e corresponde à fase de planejamento e ao design da proposta de aprendizagem. Nesta fase foi realizado o planejamento e se definiram todas as questões referentes à elaboração da proposta, tais como objetivos, conteúdo, estratégias, atividades e seleção de mídias e recursos. Foram também elaborados os instrumentos mapa de aprendizagem (8 mapas) e matriz do DI (13 matrizes).

A terceira fase do DI, de desenvolvimento, é o momento em que é estruturado tudo o que foi planejado nas etapas anteriores. Nesta fase foi definido o AVA Moodle, disponibilizado pelo projeto EnsineOnline, ocorrendo ainda a criação do curso "Sala de Apoio-Matemática" e a configuração do ambiente, concentrando todas as atividades planejadas nos mapas e matrizes do DI.

O segundo momento compreendeu a implementação da proposta, que corresponde à fase de desenvolvimento do DI. Primeiramente, foi realizado o cadastro dos alunos e do professor no AVA; após o cadastro, foram ofertadas 2 horas/aula de ambientação para que os 


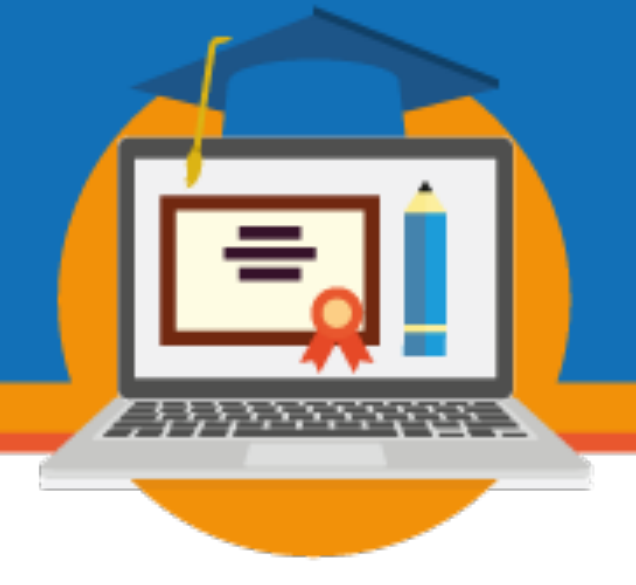

participantes pudessem se familiarizar e explorar os recursos de informação e comunicação a serem utilizados no decorrer do curso. A aplicação da proposta teve duração de 8 semanas, com disponibilização das atividades em módulos, atendimento presencial pela pesquisadora no laboratório de informática da escola, acompanhamento e feedback dos participantes sobre as atividades e intervenções na proposta de DI a partir do feedback recebido dos alunos.

O terceiro momento correspondeu à última fase do DI: a avaliação da proposta. Desta forma, após o término das atividades no AVA Moodle, foi aplicado um questionário avaliativo aos alunos e ao professor uma entrevista. Foram retirados do AVA Moodle os relatórios disponibilizados pelo sistema.

Neste estudo de avaliação do DI aberto implementado, apresentaremos os dados coletados por meio da observação realizada no decorrer da aplicação da proposta e do questionário avaliativo aplicado aos 11 alunos no final do curso.

\section{Avaliação do Design Instrucional}

No decorrer da fase de implementação da proposta, com base nas observações, foi realizada a avaliação da proposta, considerando como principal variável o aluno. A partir do feedback oferecido pelos alunos e da realização das atividades, foram realizados os seguintes ajustes à proposta inicial do curso: inclusão de duas atividades práticas, ampliação do atendimento no laboratório e redefinição de datas para entrega das atividades.

Enquanto avaliação da proposta, o questionário teve como objetivo verificar as percepções quanto às contribuições do AVA no processo de ensino-aprendizagem na disciplina de Matemática.

Foi questionado aos alunos ${ }^{2}$ se eles acreditam que o formato de apresentação de conteúdos e atividades propostas, com o auxílio do AVA Moodle, interferiu na aprendizagem deles. Todos os alunos afirmaram que a forma como a tecnologia foi utilizada contribuiu

${ }^{2}$ Os alunos foram identificados pela letra A e acrescidos do número para diferenciar os 11 alunos participantes da pesquisa. 


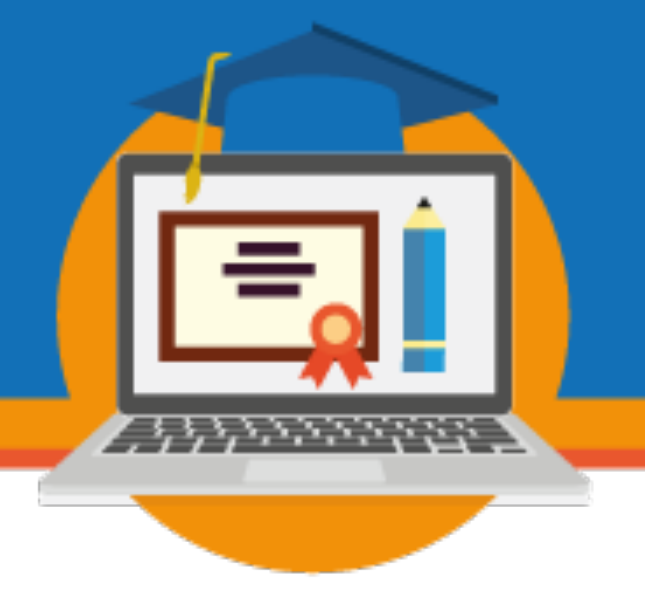

positivamente para o processo de ensino e de aprendizagem, trazendo como justificativa o conhecer outros recursos, as atividades extras para além da sala de aula, a possibilidade de aprender mais sobre um determinado conceito, sanar dúvidas e o uso de diferentes recursos para estudar os mesmos conceitos trabalhados em sala de aula.

"Porque as atividades propostas na sala virtual ajudaram a aprender mais sobre o conteúdo de
Matemática. Tirarmos as dúvidas ou aprendermos mais sobre os conteúdos trabalhados na sala de
aula. Este ambiente ajudou muito". (Al)
"Porque os recursos que tinha na sala virtual fez com que eu desenvolvesse melhor a aprendizagem". (A5)

"Porque eu aprendi mais e aprendi que não é só com o caderno e lápis que você pode estudar a matemática, mas sim utilizar diferentes recursos que existem.” (A7)

Além da contribuição positiva para o processo de ensino e aprendizagem, 10 dos 11 alunos afirmaram que a sala de apoio influenciou o modo como as aulas presenciais de matemática ocorrem e descreveram algumas mudanças:

\footnotetext{
"Notei que a partir do estudo extra realizado na sala virtual, tive menos dificuldades nas aulas, entendi melhor o conteúdo e as atividades realizadas em sala de aula” (A3).

"Percebi que passei a participar mais da aula de Matemática. Acredito que isso ocorreu porque comecei a entender melhor o conteúdo" (A6).

“Antes do estudo na sala virtual, minhas notas na disciplina de Matemática eram baixas. Agora minhas notas melhoraram, pois tive mais chances de aprender" (A7).

"Entre a sala de aula e a sala virtual, consegui relacionar o conteúdo trabalhado. Assim, muitas vezes quando o professor ia explicar a matéria, algumas coisas eu já tinha lido ou assistido a um vídeo na sala virtual que falava sobre o mesmo conteúdo" (A11).
}

Os alunos também foram questionados quanto aos conceitos e atividades de Matemática trabalhados na sala de apoio. Todos acreditaram que foram adequados e suficientes para a aprendizagem.

\footnotetext{
"Porque, como eu não sei muito bem matemática, com essa 'nova sala de aula' eu consegui entender mais sobre o conteúdo" (Al).

"Porque tudo que agente aprendeu na sala virtual ajudou muito no meu aprendizado em sala de aula" (A7).
}

\section{SEMINÁRIO DE EDUCAÇÃO A DISTÂNCIA}




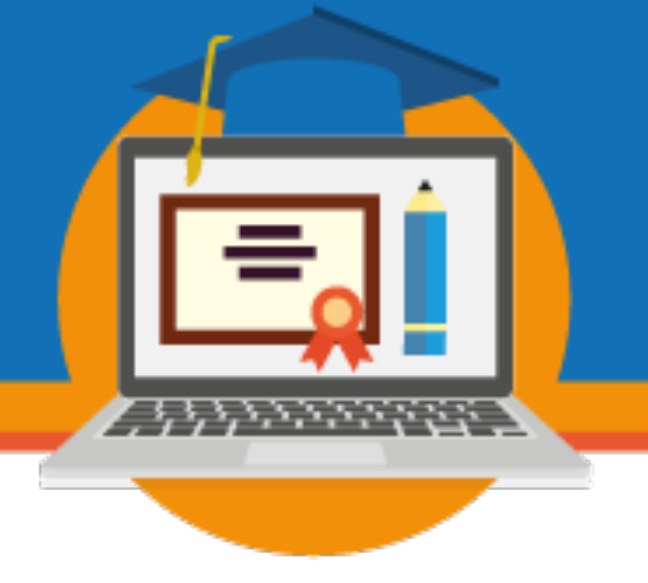

Os recursos e ferramentas utilizados pelos alunos no AVA Moodle na sala de apoio foram avaliados pelos alunos como sendo muito bons ( 9 alunos) e bons ( 2 alunos). Os alunos apresentam algumas justificativas para a avaliação dos recursos e ferramentas:

\footnotetext{
“A maioria dos recursos e ferramentas presentes na sala virtual, eu nunca havia utilizado. Só conhecia o editor de texto, de planilhas e de slides. O estudo na sala de apoio ajudou além de aprender o conteúdo de matemática, a conhecer e aprender a utilizar outros recursos” (A3).

"Achei muito legal os recursos e ferramentas da sala virtual, porque foram formas diferentes de abordar o mesmo conteúdo, com diferentes recursos” (A8).
}

Ao questionar os alunos sobre o que eles acharam de mais e menos relevante na sala de apoio, todos afirmaram que nada foi menos relevante e listaram pontos relevantes.

\footnotetext{
“Achei tudo relevante. Todas as atividades e recursos (vídeo, simulador, animação, Excel. Word, etc.) foram relevantes para meu aprendizado" (A4).

“Posso citar como relevante a qualidade dos conteúdos" (A6).

“Acho que o mais relevante, além das atividades e dos recursos, é ofato dos alunos quererem participar desta nova forma de estudo. Quanto aos recursos e atividades, achei mais relevante a calculadora gráfica, o simulador e oxcel" (A11).
}

Durante a realização da proposta, muitos diálogos e ações foram estabelecidos com o objetivo de auxiliar os alunos nas dificuldades encontradas quanto ao AVA e/ou na resolução de alguma atividade. Ao questionar os alunos se o Moodle foi um ambiente difícil de navegar, todos afirmam que não tiveram dificuldade e, no momento em que algumas dificuldades pudessem aparecer, receberam suporte pedagógico e tecnológico.

O design de um AVA compreende a organização e a aparência do ambiente. Aos alunos foi questionado quando ao design da sala de apoio, sendo avaliado pelos alunos como muito bom.

“Achei a sala bem organizada e legal” (A3).

"Porque a sala ficou bem organizada, assim conseguimos se orientar e realizar as atividades propostas” (A8). 
A proposta inicial do DI era os alunos realizarem as atividades da sala de apoio no laboratório de informática da escola ou em casa, caso tivessem acesso a um computador conectado à internet. Quanto ao acesso à sala de apoio fora do ambiente escolar, somente dois alunos afirmaram que o fizeram. Sabemos que o acesso à tecnologia não é igual para todos, e a justificativa para o não acesso ao ambiente em casa foi o fato de não terem computador e/ou acesso à internet.

"Porque não tenho computador com acesso à internet. Então, utilizei o laboratório da escola" (A1).

"Porque não tenho computador e, com o celular é difícil de realizar as atividades" (A7).

Além da pouca utilização do ambiente fora da escola, outro fator que chamou a atenção foi a não participação nos "Fóruns de Dúvidas" presentes em todos os módulos de ensino. A não participação nos fóruns foi justificada pelos alunos pela presença da pesquisadora em todos os encontros no laboratório de informática da escola, enquanto facilitadora e pela ausência de dúvidas durante a realização das atividades propostas.

"Porque a professora ou pesquisadora, estava sempre presente e atendia quando tínhamos dúvida" (A2).

"Porque não tínhamos dúvida” (A3).

Para finalizar a avaliação sobre a proposta de DI, aos alunos foi pedido que deixassem observações sobre o trabalho desenvolvido e descrevessem o que levariam da experiência com a sala de apoio à Matemática.

"Esse trabalho foi muito bem pensado e planejado. Gostei muito, não tenho nada a reclamar. $O$ estudo através da sala de apoio me ajudou muito no aprendizado” (Al).

"Levo desta experiência, um bom desenvolvimento no meu aprendizado. O que eu não entendia na sala de aula, eu aprendi na sala de apoio. Por mim teria muito mais” (A2)

"Foi divertido e bem trabalhado. Aprendi os conteúdos de Matemática de uma forma diferente e legal" (A10).

Embora, ainda, muitas escolas e professores prefiram manter os modelos de aulas prontas, Moran (2015, p. 23) evidencia que, “dependendo da qualidade desses materiais, das atividades de pesquisa e projetos planejados e da forma de implementá-los (adaptando-os à 


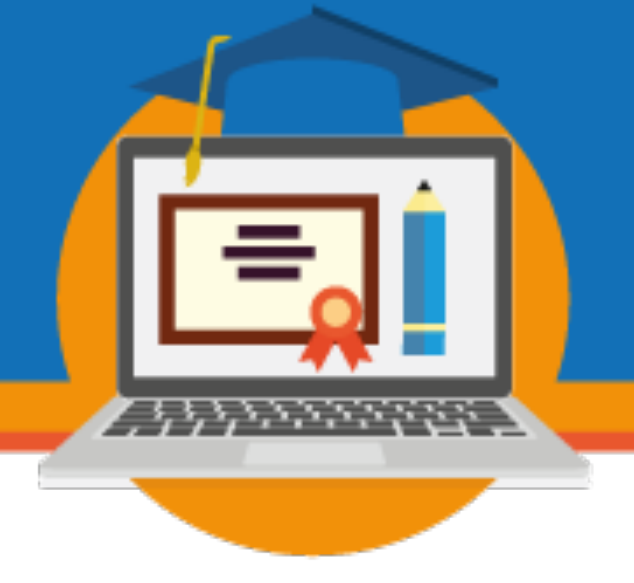

realidade local e com intensa participação dos alunos), podem ser úteis, se não são executados mecanicamente"; ou seja, o professor pode "enriquecer materiais prontos com metodologias ativas".

\section{Considerações Finais}

Neste trabalho foram apresentadas as percepções dos alunos quanto às contribuições do AVA Moodle no processo de ensino-aprendizagem na disciplina de Matemática, buscando pontos positivos e negativos. Essa avaliação compreendeu a última fase do Design Instrucional para um AVA como apoio à disciplina de Matemática.

Embora a proposta do DI para sala de apoio fosse a participação e interação entre seus participantes para além do horário da aula presencial, em diferentes horários e dias da semana, fatores como a desigualdade de acesso ao computador e/ou à internet em casa implicaram na forma como ocorreu a proposta. Pequenos grupos foram formados pelos alunos e as atividades propostas foram realizadas no laboratório de informática da escola em horários préestabelecidos; as interações entre os participantes ocorreram fora do AVA, durante os encontros.

A avaliação realizada mostrou que os alunos participantes da pesquisa manifestaram-se favoráveis ao uso do AVA Moodle como apoio ao ensino presencial na disciplina de Matemática. Para os alunos, o uso do AVA funcionou como complemento à aula presencial, possibilitando conhecer e aprender a utilizar diferentes recursos, bem como diferentes formas de abordar o mesmo conteúdo, contribuindo para o aprendizado. 


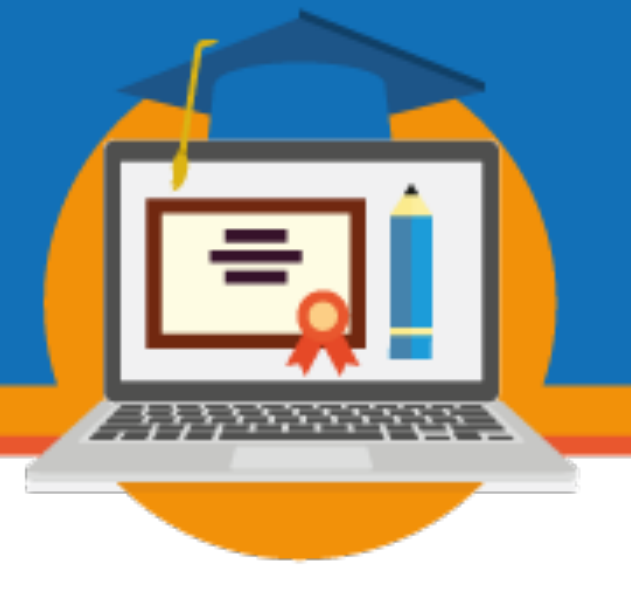

\section{Referências}

ANJOS, Alexandre M. dos. Tecnologias da informação e da comunicação, aprendizado eletrônico e ambientes virtuais de aprendizagem. In. MACIEL, Cristiano (Org.). Educação a Distância: Ambientes Virtuais de aprendizagem. Cuiabá: EdUFMT, 2013. p. 11-57.

BRASIL, Ministério da Educação. Resolução CNE/CEB $\mathbf{N}^{\mathbf{0}}$ 1, de 2016. Diário Oficial da União, Brasília, 3 de fevereiro de 2016, Seção 1, p. 6. Disponível em: $<$ http://portal.mec.gov.br/index.php?option=com docman \&view=download \&alias=33151 -resolucao-ceb-n1-fevereiro-2016-pdf\&category slug=fevereiro-2016-pdf\&Itemid=30192> .

Acesso em: 24/fev./2016.

FILATRO, Andrea. Design Instrucional na prática. São Paulo: Pearson Education do Brasil, 2008.

FILATRO, Andrea. Design Instrucional contextualizado: educação e tecnologia. 3 ed. São Paulo: Editora Senac São Paulo, 2010.

KENSKI, Vani Moreira. Tecnologias e ensino presencial e a distância. $9^{\circ}$ ed. Campinas, SP: Papirus, 2012.

MARTINS, Heloisa Helena Teixeira de Souza. Metodologia qualitativa de pesquisa. Educ.Pesquisa. São Paulo, v. 30, n. 2, p. 289-300, ago. 2004. Disponível em: $<$ http://www.scielo.br/scielo.php?script=sci_arttext\&pid=S151797022004000200007\&lng=en \&nrm=iso>. Acesso em: 23/Out./2015.

MORAN, José Manuel. Mudando a educação com metodologias ativas. Coleção Mídias Contemporâneas. Convergências Midiáticas, Educação e Cidadania: aproximações jovens. Vol. II Carlos Alberto de Souza e Ofelia Elisa Torres Morales (orgs.). PG: Foca FotoPROEX/UEPG, 2015. Disponível em:< http://www.scoop.it/t/educacao-humanistainovadora . Acesso em: 29/fev./2016.

STAKE, Robert E. Investigación con estudio de Casos, 5. ed. reimpressão. Tradução: Roc Filella. Madrid, Espãna: Ediciones Morata, S. L., 2010.

SVENSSON, Ann. Instructional-design theories applied on a web-based learning application. Fifth International Conference on Information Technology: New Generations, IEEE, 2008. $\quad$ p. 845-850. Disponível em: < http://dl.acm.org/citation.cfm?id=1396808.1397564\&coll=DL\&dl=GUIDE $>$. Acesso em: $02 /$ set./2015. 